\title{
The Effect of Electricity Shortages on South African SMEs
}

\author{
Chantelle Viljoen ${ }^{1}$ and Jean Struweg ${ }^{2 *}$ \\ ${ }^{1}$ Department of Finance and Investment Management, University of Johannesburg \\ ${ }^{2}$ Department of Finance and Investment Management, University of Johannesburg \\ * Corresponding author
}

\begin{abstract}
SMEs are viewed as drivers of economic growth and development due to the contribution made to the economy in terms of job creation and the increase of production and export volumes. Due to the recent increase of loadshedding within South Africa and the vital role that SMEs play with regards to economic growth and development, this article examines the relationship between electricity consumption and GDP, in order to comment on the effect that the national electricity shortage has had on South African SMEs. The authors conclude that a $1 \%$ decrease in electricity consumption will lead to a $4.23 \%$ decrease in GDP and since South African SMEs contribute in the region of 57\% to GDP we conclude that electricity shortages, or load shedding negatively impacts the financial performance of SMEs as well as their ability to remain competitive and successfully engage in business.
\end{abstract}

Keywords: SME's; Load shedding; Economic growth; Electricity shortages, financial performance

\section{Introduction}

Small and medium enterprises (SMEs) are viewed as drivers of economic growth and development due to the material contribution SMEs make to the economy in terms of job creation, the increase of production and export volumes as well as the introduction of innovation and entrepreneurial skills (NCR, 2011). SMEs make up $91 \%$ of formalised businesses, provide employment to about $61 \%$ of the labour force and total economic output from SMEs contributes between 52\% and 57\% of the Gross Domestic Product (GDP) of South Africa (Abor \& Quartey, 2010).

Since 2008, the South African power utility company, Eskom, has been implementing electricity load reduction with the aim of reducing the excessive pressure on the national grid, to protect the power system from a total blackout, which can take days to repair (Friskin, 2011). This practice is commonly referred to as loadshedding. Eskom generates approximately $95 \%$ of South Africa's electricity, so it is a significant stakeholder in terms of electricity supply in South Africa.Loadshedding is implemented when the demand for electricity exceeds the supply, which involves Eskom switching off the electricity supply to parts of the network, in a controlled manner, to stabilise the level of supply and demand, leaving many customers in the dark and decreasing economic growth (Friskin, 2011).

As SMEs play a vital role in the growth and development of the South African economy, this article aims to establish the effect that loadshedding has had on SMEs within South Africa.

\section{Literature Review}

The definition of South African SMEs based on the National Small Business Act 1996, as amended in 2004, specifies different definitions for SMEs in each industry sector, including number of employees, turnover, and value of assets, excluding fixed property.

A summary of the definition of SMEs by sector, is presented in table 2.1. 
TABLE 2.1: The Definition of SMEs in South Africa

\begin{tabular}{|c|c|c|c|}
\hline Sector & $\begin{array}{l}\text { Full Time } \\
\text { Employees }\end{array}$ & $\begin{array}{l}\text { Total Annual } \\
\text { Turnover } \\
\text { (R' million) }\end{array}$ & $\begin{array}{c}\text { Total Asset Value (Excluding Fixed } \\
\text { Property) } \\
\text { (R'million) }\end{array}$ \\
\hline Agriculture & $\leq 100$ & 5 & 5 \\
\hline Mining and Quarrying & $\leq 200$ & 39 & 23 \\
\hline Manufacturing & $\leq 200$ & 51 & 19 \\
\hline Electricity, Gas and Water & $\leq 200$ & 51 & 19 \\
\hline Construction & $\leq 200$ & 26 & 5 \\
\hline Retail, Motor trade and Repair services & $\leq 200$ & 39 & 6 \\
\hline $\begin{array}{c}\text { Wholesale trade, Commercial agents and Allied } \\
\text { services }\end{array}$ & $\leq 200$ & 64 & 10 \\
\hline Catering, Accommodation and Other trades & $\leq 200$ & 13 & 3 \\
\hline Transport, Storage and Communications & $\leq 200$ & 26 & 6 \\
\hline Finance and Business Services & $\leq 200$ & 26 & 5 \\
\hline Community, Social and Personal services & $\leq 200$ & 13 & 6 \\
\hline
\end{tabular}

Source: Adapted from Edinburg Group (2012).

SMEs can thus be classified as small to medium size businesses, in a wide range of economic sectors that falls within the above parameters in terms of full time employees, annual turnover and net asset value, excluding fixed property. SMEs are regarded as a vital contributor to sustainable economic growth due to their unique local flavour and labour-intensive nature (Lawless, McCann \& Calder, 2014; NCR, 2011; Abor \& Quartey, 2010). Robu (2013) stated that SMEs could be classified as the backbone of any economy due to the increase in competitiveness and technological improvements that SMEs encourage within the market, again highlighting the importance of SMEs within an economy.

During 2004 it was estimated that SMEs contributed to roughly 34.8\% to the South African GDP and employed roughly $53.9 \%$ of the total labour force (NCR, 2011). More recently, research has indicated that SMEs make up $91 \%$ of formalised businesses, provide employment to about $61 \%$ of the labour force and contributes to approximately 57\% of the GDP in South Africa (Abor \& Quartey, 2010). Due to the fast growing global economy, poor infrastructure and the increase of natural disasters, electricity shortages have become a common, worldwide phenomenon.

In the past, the effect of electricity shortages would not have been so widespread, but due to growing dependence on electricity, electricity can be classified as a key input in the economic activity process (Hu, Guo, Wang, Zhang \& Wang, 2015) and electricity shortages can have extensive negative effects on economies and other institutions. Kantar and Keskin (2013) further highlighted the importance of electricity by stating that 'electricity is the foundation of economic growth...' Thus researching the effects of electricity shortages, on not only the GDP, but tracing the effects through to smaller economic participants will assist in gaining a better understanding of the current economic and financial state, in order to find practical solutions to some of the problems that small and medium business owners in South Africa are currently faced with. Ado and Josiah (2015) conducted a study regarding the effect that electricity shortages have on SMEs in North East Nigeria and found that power failures have a significant negative impact on the operations of SMEs due to the fact that smaller business operators are generally unable to afford back-up generators.

Due to the critically important role that SMEs play in the economic growth of a country and considering that South African SMEs contribute to roughly 57\% of the country's GDP (Abor \& Quartey, 2010), it is argued that if a causal relationship between electricity consumption and economic growth is confirmed, the findings can be used to consider the effect that the increase in loadshedding has had on SMEs in South Africa. This is significant as much of the literature regarding South African SMEs main focus is on issues surrounding funding options (NCR, 2011) but not much work has been done on the effect of electricity shortages on SMEs.

Several authors have investigated the empirical relationship between electricity consumption and economic growth, employing different methodologies and examining different sets of data, however, most authors have reached different results. Many authors have tested whether electricity consumption Granger causes economic growth or vice versa and this is still a frequently debated topic (Ighodaro, 2010). This ongoing debate can be 
attributed to the difference in electricity consumption patterns in the different economies that have been examined (Ighodaro, 2010).

Onuonga (2012) found that in Kenya economic growth Granger causes electricity consumption. Chen, Kuo and Chen (2007) observed a long-run relationship between electricity consumption and economic growth in 10 Asian countries and stated that a large supply of electricity will lead to economic growth. Cheng, Wong and Woo (2013) agreed with the findings of Chen, Kuo and Chen (2007) when they concluded that in China growth in electricity generation Granger causes growth in GDP, but not vice versa. Kumar, Stauvermann and Patel (2015) studied the relationship between electricity consumption and economic growth in Gibraltar and also determined that electricity consumption causes economic growth. A study conducted by $\mathrm{Hu}$, Guo, Wang, Zhang \& Wang (2015) found that in the short-run there is a causal relationship between economic growth and electricity consumption in China's industrial sector, but in the long-run the relationship changes direction and evidence indicates that electricity consumption Granger causes economic growth, but not vice versa.

Erol and Yu (1987) found evidence that support the presence of a bi-directional causal relationship in Japan and Italy, meaning that while electricity consumption Granger causes economic growth, economic growth also Granger causes electricity consumption. In layman's terms this can be interpreted as follows:

Any change in electricity consumption will lead to a change in economic growth, but a change in economic growth will also lead to a change in electricity consumption.

While Wolde-Rufael (2005) found no causal relationship between electricity consumption and economic growth in South Africa, a few years later, in a revised study, Wolde-Rufael (2009) confirmed the presence of a causal relationship between electricity consumption and economic growth in South Africa. The difference in results can perhaps be attributed to a higher dependency on electricity by South African businesses as well as the introduction of loadshedding in 2008, but Wolde-Rufael (2009) suggested no possible reasons or explanation for the different outcomes.

The above findings agree to a study conducted by Payne (2010) who stated that there are only four possible relationships that exist between electricity consumption and economic growth, namely:

- Electricity consumption is Granger caused by economic growth;

- Economic growth is Granger caused by electricity consumption;

- No causal relationship exists between electricity consumption and economic growth; and

- Electricity consumption Granger causes economic growth, and economic growth Granger causes electricity consumption.

\section{Data}

In order to examine the relationship between electricity consumption and economic growth, the author examined two sets of time series data namely "P4141 Electricity generated and available for distribution (201603)" and "P0441 Gross Domestic Product (Quarterly) (2015Q4)", obtained from Statistics South Africa.

TABLE 3.1: Data Summary

\begin{tabular}{l|l|l}
\hline & Electricity Generated & Gross Domestic Product \\
\hline Series Analysed & ELEKTS10 & GDP at market price \\
\hline Unit & Gigawatt Hours & Rand Million \\
\hline Data Frequency & Monthly & Quarterly \\
\hline Period & January 1885 - March 2016 & 31 March 1998 - 31 December 2015 \\
\hline
\end{tabular}

Source: Authors' own summary

For the purpose of the study it is assumed that the data (electricity generated) represent the actual electricity usage of the country, as it is expected that electricity producers would adjust their output to match the demand in order to minimise overproduction that can lead to wastage. Due to the different frequencies of data available, a quarterly sample, of 72 observations is selected, covering a period of 31 March 1998 up to and including 30 September 2015. This period is selected as the data set would reflect the effect of the 2008 financial crisis and also includes a period prior to the implementation of loadshedding $(1998-2007)$ and a period that reflects the effect of loadshedding $(2008-2015)$. 
The data set is summarised in figure 3.1 below in order to illustrate the relationship between electricity usage and economic growth. The graph indicates that there is a relationship between electricity production and economic growth as the graph illustrates that an increase in electricity production leads to an increase in economic growth and a decrease in electricity production leads to a decrease in economic growth.

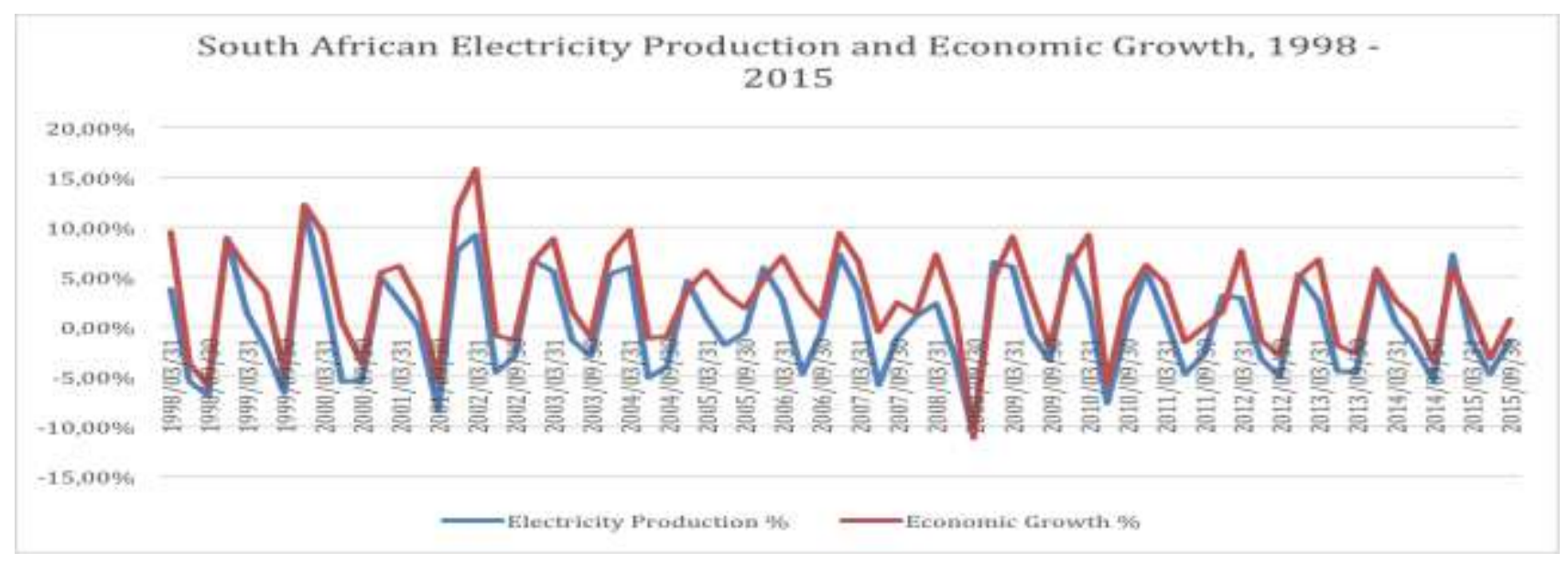

Fig. 3.1: South African Electricity Production and Economic Growth, 1998 - 2015

Source: Authors' own induction

A statistical summary of the descriptive statistics of the data is set out in table 3.2 below:

TABLE 3.2: Descriptive statistics for South Africa's real GDP and Electricity Consumption in $1998-2015$.

\begin{tabular}{|l|c|c|}
\hline & $\begin{array}{c}\text { GDP } \\
\text { (R' Million) }\end{array}$ & $\begin{array}{c}\text { CONSUMPTION } \\
\text { (Gigawatt Hours) }\end{array}$ \\
\hline Mean & 533768 & 19072 \\
\hline Maximum & 1027026 & 21952 \\
\hline Minimum & 180610 & 14898 \\
\hline Std. Dev. & 261025 & 1846 \\
\hline
\end{tabular}

Source: Eviews 9

Table 3.2 above indicates that the average GDP between 1998 and 2015 was R533 768 million while the average amount of electricity consumed in the same period was 19072 Gigawatt hours. The highest GDP earned throughout the period was R1 027026 million and the lowest GDP recorded was R180 610 million. During the sample period electricity consumption did not exceed 21952 Gigawatt hours and the lowest number of Gigawatt hours consumed was 14 898. The standard deviation indicates the amount of variation of the numbers within the data set, compared to the mean.

\section{Research Methodology}

Since the purpose of this article is to determine whether there is a statistical relationship between the variables electricity consumption and GPD, to enable the author to comment on the effect that electricity shortages have on SMEs in South Africa, a log-linear regression model on the data set (as described above) will be run, using Eviews 9, a statistical analysis programme.

The log-linear regression model will confirm the presence of a relationship and also assist in determining whether a $1 \%$ change in the independent variable, electricity consumption will lead to a $x \%$ change in the dependent variable, GDP. After the data is imported into Eviews 9, the data set will be logged and the Phillips Peron unit root test (Perron, 1983) will be employed. Directly estimating the regression model may produce spurious regression results as the data set might be non-stationary, thus the unit root test will be performed to 
establish whether the data set is stationary and to confirm that inferences made from the estimated model are valid.

After it has been confirmed that the data set is stationary, the logged data will be used to estimate a loglinear regression model. The regression model will be statistically analysed to confirm the significance of the model. If the estimated model is significant, the researcher can report the relationship between the dependent and independent variable and draw inferences from the statistical analysis. The statistical findings will be supplemented by secondary data, consisting of the results of two recent SME surveys conducted in South Africa by two independent bodies, in order to gain a better understanding of the effect that loadshedding has had on SMEs in South African.

\section{Results and Interpretation}

The results from the Phillips Perron unit root test (Perron, 1989) are summarised in table 5.1 below and indicate that the time series is stationary.

TABLE 5.1: Phillip Perron Unit Root Test (Perron, 1989)

\begin{tabular}{l|l|l|l}
\hline \multicolumn{2}{l|}{} & & \\
\hline \\
Null Hypothesis: Time Series has a Unit Root & Adj. t-Stat & Prob.* $^{*}$ \\
\hline Phillips-Perron test statistic & & & -3.42519 \\
\hline Test critical values: & & -3.52562 & 0.0132 \\
\hline & $1 \%$ level & -2.90295 & -2.5889 \\
\hline
\end{tabular}

Source: Eviews 9

As the t-statistic of $-3,43$ is greater than $(>) 2$ and the probability of 0,0132 is less than $(<) 0.05$, both indicators are significant and we can reject the null hypothesis that the time series has a unit root and we can assume that the data is stationary. As the time series is stationary we can estimate a log-linear regression model, which is assumed to be free from error.

The summary of the estimated model can be viewed in table 5.2 below. After it has been confirmed that the estimated model is significant, the research will be able to confirm or reject the presence of a relationship between electricity consumption and GDP.

TABLE 5.2: Model Estimation

\begin{tabular}{|l|r|r|r|r|}
\hline Variable & \multicolumn{1}{|c|}{ Coefficient } & \multicolumn{1}{|c|}{ Std. Error } & Prob. \\
\hline C & & & -7.71362 & 0 \\
\hline LOG(CONSUMPTION) & -28.65441 & 3.714782 & 11.22915 & 0 \\
\hline & 4.2342 & 0.377072 & \\
\hline R-squared & & & 13.0573 \\
\hline Adjusted R-squared & 0.643028 & Mean dependent var & 0.530246 \\
\hline S.E. of regression & 0.637928 & S.D. dependent var & 0.580519 \\
\hline Sum squared residual & 0.319062 & Akaike info criterion & 0.64376 \\
\hline Log likelihood & 7.12602 & Schwarz criterion & 0.605696 \\
\hline F-statistic & -18.8987 & Hannan-Quinn criter. & 0.46154 \\
\hline
\end{tabular}

Source: Eviews 9 
Again examining the t-statistic and the probability we can see that the t-statistic of 11,23 is greater than $(<)$ 2 and the probability of 0 is less than $(<) 0,05$ indicating that the estimated model is highly significant.

The R-squared of 0,6430 is also very high and suggests that electricity consumption can be used to explain $64,30 \%$ of the change recorded in GDP and only 35,70\% of the recorded change in GDP can be attributed to other factors (whether internal or external). Accordingly, a one-percentage change in electricity consumption will lead to $4.23 \%$ change in GDP, ceteris paribus. Thus, confirming the presence of a long run, casual relationship between electricity consumption and GDP in South Africa, strengthening the findings of WoldeRufael (2009).

From the above empirical results the researcher can make the inference that as a one percentage decrease in electricity consumption will lead to a $4.23 \%$ decrease in GDP and previous research has indicated that South African SMEs contribute to roughly 57\% of GDP (Abor \& Quartey, 2010), we can assume that electricity shortages, or loadshedding has and will continue to negatively affect the financial performance of South African SMEs.

In the recent 2015 SME Survey, conducted by World Wide Worx, a South African research company, the authors of the survey found that $71 \%$ of respondents consider power failures to be the biggest external threat to their business, which can be attributed to the lack of financing and resources available to SMEs to overcome these challenges that imminent power failures present (SMESurvey, 2015). The BDO Loadshedding Survey (2014) found that $31 \%$ of all respondents felt that loadshedding had a highly negative impact on their operating costs, while $29 \%$ of respondents felt that loadshedding has had a highly negative effect on their level of service delivery. $67 \%$ of respondents surveyed felt that loadshedding decreased their competitiveness and $69 \%$ of respondents reported a decrease in turnover. Respondents also reported that loadshedding resulted in their companies missing important deadlines or delivery times, important office automation systems begin offline, being unable to communicate with clients and being unable to continue with their production or manufacturing processes.

Thus electricity shortages, or loadshedding does not only negatively affect the bottom line of South African SMEs, but impacts on their entire business process from manufacturing, communication, administration and service delivery, which can lead to much greater long-run difficulties (poor levels of customer satisfaction or a damaged reputation).

\section{Conclusion}

From the above it is clear that electricity shortages and loadshedding has not only negatively affected the financial performance of South African SMEs, but also decreased their competitiveness within their specific industry, which can be attributed to the lack of infrastructure and financial resources available, to effectively manage the effect of loadshedding, as well as larger companies.

SMEs also reported that loadshedding can lead to important deadlines being missed and being unable to communicate with clients, which in the long run likely affects their customer satisfaction and retention rates, ultimately effecting their reputation and overall profitability.

To conclude, electricity shortages have had a highly negative impact on SMEs within South Africa. Not only are we able to trace the financial impact through to GDP and a weaker economy, but we also conclude that loadshedding creates barriers that prevent SMEs to produce and manufacture products, offer good service delivery to customers on time, all which in the long-run, will continue to negatively affect SMEs as they struggle to regain client confidence and market competitiveness.

\section{References}

[1] Abor, J. \& Quartey, P. (2010). Issues in SME Development in Ghana and South Africa. International Research Journal of Finance and Economics, 2010(39), pp. $218-228$.

[2] Ado, A. \& Josiah, M. M. (2015). Impact of Deficient Electricity Supply on the Operations of Small Scale Businesses in North East Nigeria. International Journal of Business and Economic Development, 3(1), pp. 20 - 30.

[3] The Banking Association of South Africa (2015). Available: http://www.banking.org.za/. (Accessed 17 April 2015)

[4] Cheng, Y. S., Wong, W. K. \& Woo, C. K. (2013). How Much Have Electricity Shortages Hampered China's GDP Growth? Energy Policy, 55(2013), pp. 369 - 373. 
http://dx.doi.org/10.1016/j.enpol.2012.12.015

[5] Chen, S., Kuo, H. \& Chen, C. (2007). The relationship between GDP and Electricity Consumption in 10 Asian Countries. Energy Policy, 35(2007), pp. 2611 - 2621.

http://dx.doi.org/10.1016/j.enpol.2006.10.001

[6] Edinburgh Group (2012). Growing the global economy through SMEs. Available: http://www.edinburghgroup.org/media/2776/edinburgh_group_research_-_growing_the_global_economy_through_smes.pdf (Accessed 18 May 2016).

[7] Erol, U. \& Yu, E. S. H. (1987). On the Causal Relationship between Energy and Income for Industrialized Countries. $J$ Energy Dev, 13, pp. $113-122$.

[8] Friskin, D. (2011). Evaluating the Effect of the Energy and Financial Crises on Electricity Production in South Africa An Exponential Smoothing Approach. South African Statistical Journal Proceedings: Proceeding of the $53^{\text {rd }}$ Annual Conference of the South African Statistical Association for 2011, Nov, pp. 35 - 46.

[9] Hu, Y., Gu, D., Wang, M., Zhang, X. \& Wang, S. (2015). The Relationship between Energy Consumption and Economic Growth: Evidence from China's Industrial Sectors. Energies, 2015(8), pp. 9392 - 9406. http://dx.doi.org/10.3390/en8099392

[10] Ighodaro, C. A. U. (2010). Co-integration and Causality Relationship between Energy Consumption and Economic Growth: Further Empirical Evidence for Nigeria. Journal of Business Economics and Management, 11(1), pp. 97 -111. http://dx.doi.org/10.3846/jbem.2010.05

[11] Kumar, R. R., Stauvermann, P. J. \& Patel, A. (2015). Nexus between Electricity Consumption and Economic Growth: A Study of Gibraltar. Econ Change Restruct, 48(2015), pp. $119-135$. http://dx.doi.org/10.1007/s10644-014-9156-0

[12] Kantar, E. \& Keskin, M. (2013). The Relationship between Electricity Consumption and GDP in Asian Countries, Using Hierarchical Structure Methods. Physica A, 392(2013), 5678 - 5684. http://dx.doi.org/10.1016/j.physa.2013.07.029

[13] Lawless, M., McCann, F., \& Calder, T. I. (2014). SMEs in Ireland: Contributions, credit and economic crisis. Policy Studies, 35(5), pp. $435-457$. http://dx.doi.org/10.1080/01442872.2014.886681

[14]BDO Loadshedding Survey Available: http://www.bizcommunity.com/f/1506/BDO_Load_Shedding_Results_....pdf (Accessed: 25 May 2016).

[15] National Credit Regulator (NCR). (2011). Literature Review on Small and Medium Enterprises' Access to Credit and Support in South Africa. Available: http://www.ncr.org.za/pdfs/Literature\%20Review\%20on\%20SME\%20Access\%20to\%20Credit\%20in\%20South\%20Af rica_Final\%20Report_NCR_Dec\%202011.pdf. (Accessed: 23 May 2016).

[16] Onuonga, S. M. (2012). The Relationship between Commercial Energy Consumption and Gross Domestic Income in Kenya. The Journal of Developing Areas, 46(1), pp. 305 - 308. http://dx.doi.org/10.1353/jda.2012.0022

[17] Payne, J. E. (2010). A Survey of the Electricity Consumption-Growth Literature. Appl Energy, 87, pp. 723 - 731. http://dx.doi.org/10.1016/j.apenergy.2009.06.034

[18] Perron, P. (1989). The Great Crash, the Oil Price Shock and the Unit Root Hypothesis. Econometrica, 57, pp. 13611401. http://dx.doi.org/10.2307/1913712

[19] Robu, M. (2013). The Dynamic and Importance of SMEs in Economy. The USV Annals of Economics and Public Administration, 13(17) pp. $84-89$.

[20] SMESurvey (2015). Available: http://www.smesurvey.co.za/reports/SME\%20Survey\%202015\%20summary.pdf (Accessed 17 April 2016).

[21] Wolde-Rufael, Y. (2005). Energy Demand and Economic Growth: The African Experience. Journal of Policy Modeling, 27, pp. $891-903$. http://dx.doi.org/10.1016/j.jpolmod.2005.06.003

[22] Wolde-Rufael, Y. (2009). Energy Consumption and Economic Growth: The Experience of African Countries Revisited. Energy Economics, 31(2009), pp. 217 - 224. http://dx.doi.org/10.1016/j.eneco.2008.11.005

[23] World Wide Worx (2015). Available: http://www.worldwideworx.com/. (Accessed 17 April 2015) 